\title{
CATEGORIAS DO JUÍZO PROFESSORAL: ENTRE INTERPRETACOÕES, JULGAMENTOS E IMPLICAÇÕES
}

\author{
JAQUELINE MAAS OLIVEIRA' \\ CRISTINA CARTA CARDOSO DE MEDEIROS"
}

I Universidade Federal do Paraná (UFPR), Curitiba-PR, Brasil; jaqmaas@gmail.com

II Universidade Federal do Paraná (UFPR), Curitiba-PR, Brasil; cricaccm@gmail.com

\section{RESUMO}

Este artigo tem como objetivo discutir o julgamento professoral realizado pelos agentes escolares nos momentos dos conselhos de classe de um colégio público estadual. Trata-se do conjunto de achados derivados de uma pesquisa qualitativa que teve, como principal técnica para a produção de dados, observações dos conselhos de classe e, em seguida, a análise de documentos escolares. Tais elementos foram organizados e interpretados tendo como fio condutor a teoria sociológica de Pierre Bourdieu e a análise de conteúdos de Bardin (2011). Os dados empíricos possibilitaram a categorização dos elementos observados, especificadamente, as adjetivações proferidas sobre os estudantes, o que viabilizou a constatação de que aspectos extraescolares são mais lembrados pelos educadores do que aqueles relacionados ao desenvolvimento acadêmico. Ademais, apurou-se que as expectativas prognosticadas pelos professores frente aos discentes cumpriram-se e que aspectos relacionados à estrutura familiar tiveram significância durante o julgamento.

PALAVRAS-CHAVE CONSELHO DE CLASSE • JUÍZO PROFESSORAL • AVALIAÇÃO DA APRENDIZAGEM・BOURDIEU, PIERRE. 


\section{CATEGORÍAS DEL JUICIO PROFESORAL: ENTRE INTERPRETACIONES, JUICIOS E IMPLICACIONES}

RESUMEN

Este artículo tiene el objetivo de discutir el juicio profesoral realizado por los agentes escolares durante los consejos de clase de un colegio público provincial. Se trata del conjunto de hallazgos derivados de una investigación cualitativa cuya principal técnica para la producción de datos fueron observaciones de los consejos de clase y luego, el análisis de documentos escolares. Tales elementos se organizaron e interpretaron utilizando como hilo conductor la teoría sociológica de Pierre Bourdieu y el análisis de contenidos de Bardin (2011). Los datos empíricos posibilitaron la categorización de los elementos observados y, más específicamente, las adjetivaciones relativas a los estudiantes, lo que hizo factible la constatación de que aspectos extraescolares son más recordados por los educadores que aquellos relacionados al desarrollo académico. Además, se verificó que las expectativas pronosticadas por los profesores frente a los alumnos se cumplieron y que aspectos relacionados con la estructura familiar fueron significativos durante el juicio.

PALABRAS CLAVE CONSEJO DE CLASE • JUICIO PROFESORAL • EVALUACIÓN

DEL APRENDIZAJE・BOURDIEU, PIERRE.

\section{CATEGORIES OF TEACHERS' JUDGMENT: INTERPRETATIONS, JUDGMENTS AND IMPLICATIONS}

ABSTRACT

This study aims to discuss teachers' judgment carried out by school agents during class councils at a state public school in Paraná. It consists of a set of findings from a qualitative study, based on data from class council observations followed by analysis of school documents. These elements were organized and interpreted applying Pierre Bourdieu's sociological theory and Bardin's (2011) content analysis. The empirical data allowed the categorization of the observed elements, specifically the terms used to describe the students. This led to the conclusion that non-scholastic aspects are more memorable for educators than those related to academic development. In addition, it was found that teachers' expectations of students were fulfilled, also that aspects related to family structure were significant during the class council assessment.

KEYWORDS CLASS COUNCIL • TEACHERS' JUDGMENT • LEARNING ASSESSMENT • BOURDIEU, PIERRE. 


\section{INTRODUÇÃO}

O presente artigo deriva de uma investigação que teve a intenção de compreender e identificar os elementos que compõem as categorias de juízo professoral, ou seja, interpretações e julgamentos explicitados na apreciação de resultados acadêmicos de alunos dos sextos anos de uma escola pública, nos momentos dos conselhos de classe, bem como analisar teoricamente os possíveis motivos que levam os docentes a adotarem tais critérios avaliativos, além de suas implicações na vida escolar dos estudantes.

Justifica-se o investimento nessa temática a partir do exposto por Bourdieu e Saint-Martin (2015), no texto "As categorias do juízo professoral”, quando defenderam que o julgamento professoral e as impressões sobre o outro, constituídas no espaço escolar, perduram até mesmo após a morte do agente, momento em que são mencionadas as suas características de origem, a forma de ser e estar no espaço escolar que se perpetuam. Mesmo se tratando de um contexto francês e suas pesquisas tendo sido realizadas em 1975, as afirmações dos autores se mostram atuais, principalmente 
quando demonstram também que a escola transforma adjetivos sociais em escolares, ou seja, que a vida extraescolar do aluno tem peso determinante no julgamento realizado pelos docentes e que essas implicações afetam a existência do estudante de forma intensa e complexa.

Além de buscar descrever os resultados da investigação, que objetivou realizar a inferência sobre os elementos que compõem as categorias do juízo professoral que professores de quatro turmas de sexto ano de um colégio público estadual no Paraná proferem por ocasião de conselhos de classe, procura-se neste texto resgatar a conceituação, a implementação e os significados dos conselhos de classe, optando-se por uma abordagem qualitativa de pesquisa, no contexto da descoberta. Em tal abordagem, não se objetiva testar ou comprovar teorias, e sim preencher lacunas, contribuindo para a produção de novos conhecimentos (ALVES-MAZZOTTI, 1998), especificadamente relativos à cultura da escola no que se refere ao processo de avaliação no espaço dos conselhos de classe, ${ }^{1}$ a partir de chaves de interpretação desenvolvidas pelo sociólogo Pierre Bourdieu. Citam-se como chaves utilizadas as noções de habitus (BOURDIEU, 2009), em que, a partir do componente hexis, foi possível identificar as posturas e as disposições do corpo interiorizadas no indivíduo no processo de socialização. Recorreu-se igualmente à noção de violência simbólica (BOURDIEU, 2010), o ajustamento das estruturas subjetivas e das estruturas objetivas ou, ainda, a forma incorporada da estrutura da relação de dominação que ocorre com a cumplicidade inconsciente dos que dela são vítimas e que, assim como o juízo professoral, possui impacto na ação pedagógica e na compreensão do fenômeno da avaliação da aprendizagem, especialmente relacionado aos conselhos de classe. Ainda com o intuito de melhor compreender o cenário observado e seus agentes, empregou-se a noção de capital cultural (BOURDIEU, 2015), a saber, o conjunto de bens simbólicos sob formato de qualificações intelectuais, advindos primeiramente do ambiente familiar e posteriormente do espaço escolar.

Embora, pelo tempo despendido no campo empírico, esta pesquisa não possa ser caracterizada como do tipo
1 Forquin (1993, p. 167) define cultura da escola como um espaço "que tem suas características de vida próprias, seus ritmos e seus ritos, sua linguagem, seu imaginário, seus modos próprios de regulação e de transgressão, seu regime próprio de produção e de gestão de símbolos." Ao mesmo tempo, alerta que esse conceito não deve ser confundido com a cultura escolar, esta entendida como "o conjunto dos conteúdos cognitivos e simbólicos que, selecionados, organizados, 'normatizados', 'rotinizados', sob o efeito dos imperativos da didatização, constituem habitualmente o objeto de uma transmissão deliberada no contexto das escolas." (FORQUIN, 1993, p. 167). Mafra (2003, p. 126) evidencia que os estudos preocupados em compreender a cultura da escola "buscam dar visibilidade ao que se denomina éthos cultural de um estabelecimento de ensino, sua marca ou identidade cultural, constituída por características ou traços culturais que são transmitidos, produzidos e incorporados pela e na experiência vivida no cotidiano escolar". 
etnográfico, foram utilizadas técnicas tradicionalmente associadas à etnografia, como a observação e a análise documental. Assim, realizaram-se observações dos conselhos de classe, em quatro momentos, referentes aos três trimestres de quatro turmas de sextos anos de um colégio público estadual no ano letivo de 2015. Após os conselhos de classe, no início de 2016, teve-se acesso a documentos elaborados pela equipe pedagógica, professores e secretários da escola, relativos ao mesmo ano letivo dos mesmos sextos anos. Esses documentos são: fichas individuais, que são registros alimentados principalmente pela equipe pedagógica durante atendimento a alunos e responsáveis, em que se relatam os problemas enfrentados e combinados visando à sua resolução; livro dos conselhos, elaborado e alimentado pela equipe pedagógica durante os pré-conselhos e conselhos de classe, em que se relatam brevemente as notas, os problemas de aprendizagem, as dificuldades dos alunos e sugerem-se ações para a resolução; boletins escolares; e livros de chamada dos professores. Nestes, buscaram-se escritos que denotassem os julgamentos de forma a contribuir com os dados das observações, para a análise posterior.

Entende-se que a observação permite registrar o comportamento dos agentes em seu contexto histórico e de espaço. Esta se deu de forma não estruturada, utilizando de registros escritos no momento da observação (LESSARD-HÉBERT; GOYETTE; BOUTIN, 2005), em que a pesquisadora esteve atenta às condutas dos agentes, percebendo a maneira como são encaminhados os conselhos de classe, as formas de pensar a avaliação, os julgamentos proferidos, a percepção dos profissionais quanto aos alunos passíveis de sucesso ou fracasso escolar.

Para uma análise prévia dos resultados, de forma a organizar e conseguir visualizar as informações contidas nas anotações de campo e nos documentos aos quais se teve acesso, elaboraram-se instrumentos apoiados na análise de conteúdo (BARDIN, 2011), que, associados às noções desenvolvidas por Bourdieu, serviram de base para a elaboração das categorias e a inferência dos dados.

As observações nos momentos dos conselhos de classe, aliadas aos documentos escolares, contribuíram para uma 
primeira análise e elaboração de categorias estruturadoras. Assim, utilizando dois instrumentos para a produção de dados (observação e análise documental), procurou-se estabelecer uma relação confiável entre os resultados, de modo que um validasse e complementasse o outro.

Após a delimitação da problemática, a justificativa da relevância do tema, a exposição sobre a metodologia, contendo as técnicas de produção e análise dos dados em campo empírico definido, contidos nesta introdução, divide-se este artigo em três etapas. Inicia-se por uma contextualização dos conselhos de classe, sua implementação e características. Em seguida, discorre-se sobre as classificações e julgamentos presentes na prática avaliativa, para, enfim, mostrar os dados produzidos no campo empírico e as análises correspondentes que apresentam sua sistematização para efeito de fechamento nas considerações finais.

\section{CONTEXTUALIZANDO O CONSELHO DE CLASSE}

Com relação aos aspectos históricos envolvidos na introdução da prática dos conselhos de classe no Brasil, recorre-se ao estudo de Any Dutra Coelho da Rocha, publicado em 1982, no qual a autora esclarece que a introdução da ideia dos conselhos de classe no país se deu entre os educadores do Rio de Janeiro, quando da realização de estágios e visitas ao Instituto de Pesquisas Educacionais de Sèvres, França, em 1958, os quais tiveram o objetivo de estudar as classes experimentais introduzidas no contexto francês em $1945 .^{2}$

As experiências-piloto no contexto brasileiro foram desenvolvidas no Colégio de Aplicação da Universidade Federal do Rio de Janeiro, em 1959. Seu êxito foi evidenciado pela extensão dos conselhos de classe para todas as turmas do colégio, posteriormente para outras classes experimentais em diferentes estados da nação e, após a promulgação da Lei n. 5.692/71 (BRASIL, 1971a), de forma gradativa para todo o território nacional (ROCHA, 1982).

Entende-se que o cenário da educação brasileira se demonstrava favorável à implementação dos conselhos de classe, pois, anteriormente à Lei n. 5.692/71 (BRASIL, 1971a), com

2 Nesta perspectiva, Dalben (1995) relativiza o conselho de classe no território francês, mencionando que este tinha em seus princípios um cunho classificatório e determinista, pois era utilizado para direcionar o futuro acadêmico dos estudantes conforme suas aptidões. 
3 Conforme Leite (2012), o Colégio Estadual do Paraná servia na época como referência para todo o estado, sendo sede de um complexo escolar composto de sete instituições. Também cabe destacar que o conselho de classe não recebia essa denominação na época da implementação das classes integrais. o aumento da demanda do ensino no país, houve um movimento do então Ministério da Educação e da Cultura (MEC) de alterações da organização no ensino com a descentralização do processo avaliativo, o que fez com que aos poucos os inspetores externos, que eram os grandes responsáveis pelos exames, fossem substituídos pela escola, que passa a ter mais autonomia no processo avaliativo. Assim, "os exames formais foram substituídos por um acompanhamento constante do rendimento do aluno ao longo do ano letivo" (LEITE, 2012, p. 71).

Embasando-se em Compiani (1965), Leite (2012) elucida a implementação dos conselhos de classe no Colégio Estadual do Paraná, ${ }^{3}$ que se deu juntamente à implementação do projeto de classes integrais, em 1960, as quais objetivavam resolver problemas referentes aos altos índices de reprovação e desistência dos alunos do secundário. Coordenado pela própria Ruth Compiani, que também esteve em Sèvre, o projeto das classes integrais previa reuniões semanais entre os professores para discutir o aproveitamento dos alunos e também para deliberar sobre a sua aprovação ou não no caso de não aproveitamento em uma disciplina.

Leite (2012), em sua análise dos conselhos de classe entre os anos de 1970 e 1990, evidenciou que, no estado do Paraná, desde seu princípio, havia certo distanciamento das práticas dos conselhos de classe em relação à legislação, situação essa que continua a acontecer.

A maneira como se dá a avaliação da aprendizagem no espaço escolar hoje tem relação direta com sua institucionalização, que ocorreu após proclamação da República, em 1888. Rosa Fátima de Souza (1998) investigou a implementação da escola primária graduada no estado de São Paulo no período de 1890-1910, abordando aspectos da reorganização escolar que passou a ser adotada em todo o território nacional. Segundo a autora, a sistematização e institucionalização do sistema avaliativo deu-se juntamente à implementação das escolas seriadas, ocasionando a necessidade de classificar os alunos por grau de conhecimento.

De acordo com Souza (1998), anteriormente a 1888, durante o Brasil Império, a avaliação escolar não era sistematizada. 
Os estudantes tornavam-se aptos assim que concluíam o processo. Com o advento da proclamação da República, instaurou-se a necessidade de reformas nas instituições públicas, o que, na esfera escolar, deu-se especialmente na introdução dos exames públicos. O desejo republicano era universalizar a educação popular (caráter democrático republicano), mas ao mesmo tempo ter uma escola de qualidade e prestígio, que deveria ser "austera e rigorosa" (SOUZA, 1998, p. 242). Dessa forma, a avaliação formal passou a fazer parte da reestruturação do sistema de ensino do século XIX, "baseada na graduação escolar e na necessidade de classificação e seleção permanente dos alunos" (SOUZA, 1998, p. 242). O resultado das avaliações "evidenciava não apenas a apropriação de um capital cultural socialmente valorizado e de acesso restrito na época como manifestava a qualidade do ensino ministrado pela escola" (SOUZA, 1998, p. 245).

Assim, o sistema avaliativo classificatório nasce respaldado por um projeto republicano pautado pela racionalização do tempo e espaço. A implementação da escola graduada se deu e ainda vive embebida por desejos de homogeneizar e classificar os estudantes, reproduzindo as formas de interpretar, classificar e julgar conforme os saberes valorizados.

Há no meio acadêmico certa dualidade quanto à abordagem dada ao colegiado, conselho de classe, sendo este tratado em sua realidade, ou seja, em como está de fato se efetivando no seio escolar, e, em outro viés, com cunho mais otimista, no sentido de trazer relatos de experiências positivas, tendo-o como fomentador da gestão democrática escolar. Papi (2015), ao realizar uma análise de 67 resumos de teses e dissertações que trouxeram a temática dos conselhos de classe como colegiado escolar no período entre 2002 e 2011, concluiu que o conselho de classe vem se demonstrando como espaço profícuo para a análise de diversas problemáticas no âmbito da educação. Ao observar as conclusões pontuadas nos resumos analisados, Papi (2015, p. 516) verificou que a prática dos conselhos de classe "tem marcas do tradicionalismo e da exclusão, embora também se destaquem ações democráticas que impulsionam a construção de saberes políticos”. 
Dalben (2004), autora que vem estudando o conselho de classe e que alicerça muitas das discussões sobre o tema, considera-o uma instância coletiva na escola, responsável pela avaliação da aprendizagem do aluno de forma conjunta. Para ela, o conselho está intimamente relacionado às concepções de avaliação e ensino contidas no espaço escolar, as quais interferem diretamente no modo de atuar dos agentes envolvidos no processo:

O Conselho de Classe é um órgão colegiado, presente na organização da escola, em que vários professores das diversas disciplinas, juntamente com os coordenadores pedagógicos, ou mesmo os supervisores e orientadores educacionais, reúnem-se para refletir e avaliar o desempenho pedagógico dos alunos das diversas turmas, séries ou ciclos. (DALBEN, 2004, p. 31)

A autora entende que esse espaço tem características específicas:

a) a forma de participação direta, efetiva e entrelaçada dos profissionais que atuam no processo pedagógico; b) sua organização interdisciplinar; c) a centralidade da avaliação escolar com foco de trabalho da instância. (DALBEN, 2004, p. 31)

Fernandes e Freitas (2007) pensam o conselho de classe como um espaço rico de possibilidades para a discussão das necessidades e progressos dos estudantes, espaço para troca de informação, para estabelecimento de estratégias com objetivo de favorecer a aprendizagem do aluno e também como local para o resgate do aspecto coletivo do trabalho docente, com as trocas de experiências. Alertam, porém, que, em muitas realidades escolares, o conselho de classe

[...] ou tornou-se uma récita de notas e conceitos, palco de lamúrias e reclamações ou, simplesmente, inexiste. Acontecendo dessa forma, o conselho de classe coaduna-se com a perspectiva da avaliação classificatória e seletiva, perdendo seu potencial. (FERNANDES; FREITAS, 2007, p. 36-37) 
Machado (1991, p. 12) também aponta essa contradição ao afirmar que o conselho de classe pode se desenvolver como:

[...] um mecanismo de absorção das tensões e conflitos regulando-os a favor da manutenção da estrutura vigente ou pode representar a possibilidade de inovação, se permite a realização de potencialidades inexploradas como: a participação direta e crítica de todos os envolvidos no processo pedagógico, processos avaliadores capazes de redirecionar as práticas vigentes e alternativas de integração disciplinar visando romper com a fragmentação do conhecimento.

No entanto, o que se constata é o desenrolar de uma forma de fazer o conselho de classe que vai de encontro à proposta avaliativa defendida como promotora de aprendizagem e igualdade no espaço escolar.

Tendo como suporte metodológico a etnografia, Dalben (1995, p. 112) pesquisou o conselho de classe em uma escola pública de Belo Horizonte, onde constatou a sua ineficácia, pois as propostas para resoluções de problemas pautados não se concretizaram. Notou também a ausência de tempo para que todos os professores pudessem participar das discussões e a inexistência de uma análise do significado do conselho de classe. A autora evidencia que os professores constroem uma fotografia da turma em que relatam fatos e notas desconexas entre si,

[...] como se estivessem dando conhecimento e "satisfação" a si mesmos e a seus pares daquilo que está acontecendo, especialmente com relação ao rendimento das turmas com as quais trabalham.

Considera que, no conselho escolar, a atenção fica restrita às medidas e a análise fica concentrada nas questões de ordem individual, de forma a justificar os resultados, em que o aluno é o culpado por não aprender. Segundo Dalben (1995, p. 114):

[...] as discussões não ultrapassam o cunho da avaliação pessoal de cada professor, transcorrendo um processo 
individualista e compartimentado, oposto à visão inicial do papel do Conselho de Classe como aglutinador de análises, numa perspectiva de visão global do aluno.

Assim denuncia que o papel do conselho de classe no cotidiano escolar:

[...] tem sido mais o de reforçar e legitimar os resultados dos alunos, já fornecidos pelos professores e registrar em seus diários, e não de propiciar a articulação coletiva desses profissionais num processo de análise dialética, considerando a totalidade. (DALBEN, 1995, p. 114)

A seguir à explanação do contexto histórico da realidade do conselho de classe nas escolas brasileiras, desenha-se o cenário em que esta pesquisa foi desenvolvida: trata-se de um colégio estadual de um município da região metropolitana de Curitiba, Paraná, onde foram analisadas as interpretações e julgamentos realizados por professores sobre alunos dos sextos anos nos momentos de reunião do conselho de classe, este composto por docentes (professores de Matemática, Português, Ciências, Educação Física, Arte, Geografia, História, Língua Estrangeira Moderna e Ensino Religioso) de determinada turma, juntamente com a equipe pedagógica, um representante da secretaria e um da direção escolar.

O sexto ano foi escolhido por alguns motivos, como o fato de os professores não conhecerem esses alunos previamente, pois a grande maioria (com exceção dos repetentes) adveio de escolas municipais (quinto ano), o que evitaria assim pré-julgamentos sobre os mesmos. Também se considera que o sexto ano é para os alunos uma fase complicada de transição, pois, ao passarem para o ensino fundamental II $\left(6^{\circ}\right.$ ao $9^{\circ}$ ano), mudam de escola, tendo que se adaptar à pluridocência. Orenga e Corrêa (2014) salientam que, com o ingresso em uma nova escola, de ensino fundamental II, o aluno é visto pelos professores de cada disciplina de forma diferente, o que caracteriza a fragmentação. Nesse meio, o aluno precisará adaptar-se às exigências impostas, exigências essas que podem ser diferentes para cada docente. Esse momento de transição envolve aspectos pertencentes aos 
âmbitos tanto social quanto emocional, cognitivo e biológico, sendo que muitos dos estudantes estão atravessando a puberdade. Ao entrevistar professores que lecionam em turmas de sextos anos, as pesquisadoras observaram que ora os alunos são julgados como interessados e curiosos, ora como despreparados e imaturos. As queixas principais apontadas pelos docentes estariam no fato de muitos alunos não apresentarem conhecimentos prévios necessários para acompanhar de forma satisfatória o sexto ano, bem como na falta de articulação entre as escolas municipais e estaduais (ORENGA; CORRÊA, 2014).

\section{A PRÁTICA AVALIATIVA: CLASSIFICAÇÃO E JULGAMENTO}

A partir das leituras da teoria sociológica de Pierre Bourdieu, pode-se inferir que a avaliação é um processo muito mais cruel do que simplesmente a verificação de aprendizagem, já que nesse processo é colocada em pauta não só a capacidade intelectual, mas também características sociais, morais e culturais dos alunos, favorecendo aquele indivíduo já "treinado", "socializado" pela família, com mais capital cultural compatível com a instituição. Para Resende (2017, p. 328), que aborda o sistema de ensino a partir da obra desse sociólogo francês, os exames escolares e seus vereditos correspondentes, ou seja, as classificações deles decorrentes, constituem para Bourdieu uma ocasião privilegiada para se observar a arbitrariedade pedagógica, bem como a ocultação de tal arbitrariedade. Revelam a lógica de funcionamento do sistema de ensino, cujas avaliações demonstram, ao olhar mais atento, que o que está em jogo são não somente os conhecimentos e habilidades efetivamente ensinados, mas também um conjunto de normas implícitas, de critérios difusos e inconscientes da percepção social, que configuram um verdadeiro julgamento de classe e da relação com a cultura, a partir dos parâmetros da classe dominante.

$\mathrm{O}$ texto privilegiado para compreender de modo especial tais vereditos foi escrito por Bourdieu e Saint-Martin (2015). Descreve observações sobre os sistemas de classificação dissimulada que são produzidos por práticas de gerações sucessivas, 
sendo esquemas de percepção, apreciação e de ação diante dos alunos. Esses sistemas acabam por operar na prática as estruturas objetivas e tendem a se reproduzir, como, por exemplo, nos julgamentos que ocorrem ao relacionar a avaliação à origem social de estudantes. São as classificações ou taxionomias, como referenciam os autores:

O julgamento professoral apoia-se de fato sobre todo um conjunto de critérios difusos, jamais explicitados, padronizados ou sistematizados, que Ihes são oferecidos pelos trabalhos e exercícios escolares ou pela pessoa física de seu autor. (BOURDIEU; SAINT-MARTIN, 2015, p. 213)

Compreende-se que o juízo professoral é em si a condição do professor enquanto docente. Faz parte de sua função julgar e avaliar através da ação pedagógica. O julgamento que é realizado pelos professores leva em conta não somente a aparência física, como a cor da pele, mas também o tratamento social do corpo, como a roupa que se veste e maneiras de conduta (BOURDIEU; SAINT-MARTIN, 2015). Assim, associa-se a origem social à qual o indivíduo pertence a partir de sua hexis corporal:

Bourdieu observa que a avaliação escolar vai muito além de simples verificação das aprendizagens, incluindo verdadeiro julgamento cultural, estético e, até mesmo, moral dos alunos. (NOGUEIRA; NOGUEIRA, 2014, p. 53)

Dessa forma, os autores definem a escola como uma máquina de transformação de adjetivos, convertendo adjetivos sociais em adjetivos escolares, em que as funções sociais do sistema de classificação são dissimuladas. Tais funções estão no princípio das classificações escolares e funcionam "segundo a lógica da denegação: ele [o professor] faz o que faz sob modalidades que tendem a mostrar que ele não $o$ faz" (BOURDIEU; SAINT-MARTIN, 2015, p. 217):

O professor pode tudo se permitir, incluindo as alusões mais transparentes à classificação social ("vulgar", "pesado", "pobre”, "estreito", "medíocre”, "gauche”, "desajeitado", etc.) porque é fora de cogitação, aqui, que alguém possa "pensar mal"; a neutralidade escolar não passa na 
verdade dessa extraordinária denegação coletiva que faz por exemplo com que o professor possa, em nome da autoridade que the delega a instituição escolar, condenar como escolares as produções e as expressões que apenas são o que a instituição escolar produz e exige. (BOURDIEU; SAINT-MARTIN, 2015, p. 219, grifo do original)

As categorias estruturadoras da investigação da qual deriva este artigo, a exemplo do destacado por Bourdieu e Saint-Martin (2015), também se ancoraram nas adjetivações proferidas pelos professores e equipe pedagógica. Tendo como base as etapas da análise de conteúdo especificadas em Laurence Bardin (2011) (a pré-análise ou leitura flutuante, a exploração do material e a inferência dos dados), fez-se primeiramente uma leitura geral dos dados coletados nas observações, organizados em um diário de campo em que se anotaram depoimentos e opiniões proferidas sobre os alunos. Além dessa descrição, utilizaram-se os documentos escolares para identificar qual foi o resultado acadêmico do aluno ao final do ano letivo. Na fase da exploração do material, após uma visão geral dos dados coletados, foi possível pensar em unidades de registros que pudessem fazer emergir categorias, as quais, após seu refinamento, deram origem às categorias estabelecidas (QUADRO 1). Tais categorias tiveram a função de agrupar frases semelhantes direcionadas aos discentes ao serem avaliados e que se mostraram relevantes para análise, em função das adjetivações. A análise categorial:

[...] pretende tomar em consideração a "totalidade de um texto" passando-o pelo crivo da classificação e do recenseamento, segundo a frequência de presença (ou de ausência) de itens de sentido. [...] É o método das categorias, espécie de gavetas ou rubricas significativas que permitem a classificação dos elementos de significação constitutivos da mensagem. (BARDIN, 2011, p. 42-43, grifo no original)

Dessa forma, elaborou-se o quadro abaixo, em que são consideradas as quatro categorias estabelecidas para organizar as frases, frases essas carregadas de julgamentos, sejam eles positivos ou negativos. 
QUADRO 1 - CATEGORIAS ELABORADAS A PARTIR DOS DADOS EMPÍRICOS

\begin{tabular}{|l|l|}
\hline COMPORTAMENTO & $\begin{array}{l}\text { Adjetivações relacionadas ao comportamento, formas } \\
\text { de agir do estudante no espaço escolar. }\end{array}$ \\
\hline CONTEXTO SOCIAL & $\begin{array}{l}\text { Adjetivações relacionadas ao contexto social, como a } \\
\text { origem do aluno, menções sobre os seus responsáveis, } \\
\text { etc. Subdividido em: familiar, saúde, origem e outros. }\end{array}$ \\
\hline HEXIS CORPORAL & $\begin{array}{l}\text { Componente do habitus, forma física de estar que } \\
\text { reflete sua condição de classe. São os aspectos } \\
\text { corporais externos mencionados pelos professores. }\end{array}$ \\
\hline PRODUÇÃO ACADEMMICA & $\begin{array}{l}\text { Adjetivações relacionadas diretamente ao rendimento } \\
\text { acadêmico. }\end{array}$ \\
\hline
\end{tabular}

Fonte: Elaborado por Oliveira (2017) a partir dos dados empíricos produzidos durante as observações dos conselhos de classe e análise documental.

As quatro categorias foram referenciadas nas noções e conceitos da teoria sociológica de Bourdieu e procuram estabelecer, de forma relacional, como funciona o espaço social estudado. O Comportamento e a Hexis Corporal derivam do conceito de habitus, ou seja, do sistema de disposições incorporadas no processo de socialização, que imprime maneiras de perceber, de sentir, de fazer e de pensar, levando o agente à ação (BOURDIEU, 2009). Como o habitus é indissociável das questões do corpo, da cognição e da ética, as categorias da Produção Acadêmica e do Contexto Social afunilam o olhar para o agente, localizando seu pertencimento e as ações de classificações que seu pertencimento suscita por outros.

Quanto à categoria Comportamento, as queixas mais recorrentes são relacionadas a conversa, preguiça, caráter, etc., expressos em adjetivos como: indisciplinado, preguiçoso, dissimulado, quietinho, mentiroso, disperso, imaturo, apática, sarrista, conversadeira, agitado, desligado, debochada, desatenta, resistente, cara de pau, coitadinho, trastinha, tímido, paradão, chato, falso, sem-vergonha, bebezinho, malandro, vagabundo, autista, descarada, folgadinho, danado, atrapalhado e galinha. Adjetivos declarados considerados positivos são: educado, carinhoso, participativo, excelente, comportado, responsável, esforçada, preparada, ótimo, bom, fofura e fofo. Tais adjetivos foram manifestados em frases como:

Professora de História: "Mas é fofo demais! Fofura! Destaque!"

(Anotações de campo. Conselho 2, 6D, 10/11/2015) 
Professora de Português: "Se você perguntar qualquer coisa, qualquer assunto, ele sabe falar, só que é preguiça. Ele é muito preguiçoso!"

(Anotações de campo. Conselho 3, 6D, 17/02/2016)

Professora de Matemática: "Ele é sem-vergonha! Pra mim é isso. Preguiçoso!"

(Anotações de campo. Conselho 3, 6B, 17/02/2016)

Professora de História: "Esse é largadinho. [...] Esse também é bem folgadinho."

(Anotações de campo. Conselho 3, 6C, 17/02/2016)

Professora de História: "[...] é dissimulada, descarada e mal-educada."

(Anotações de campo, Conselho 3, 6C, 17/02/2016)

Como exemplos de adjetivos referentes à Hexis corporal, temos bonitinho, lindinho, gracinha, gordinho, velha, moreninha, pequenininho, sujinho, bebezinho e largadinho, que foram verbalizados em frases como:

Professora de Ciências: "Eu acho ele tão lindinho! Adoro ele!" (Anotações de campo, Conselho 2, 6C, 10/11/2015)

Professora de Português: "É tipo um bebezinho. Ele ficou uma semana em casa na feira cultural, porque ele falou que não precisava vir e ela (a mãe) também não ligou pra ver." (Anotações de campo. Conselho 3, 6C, 17/02/2016)

Professora de Matemática: "Ele é bonitinho, uma gracinha." (Anotações de campo. Conselho 3, 6C, 17/02/2016)

Professor não identificado: "É pequenininho, um bebezinho. [...] Dá vontade de pegar no colo...”

(Anotações de campo. Conselho 3, 6C, 17/02/2016)

Na categoria Contexto Social, elencaram-se frases julgadoras relacionadas à origem do estudante, contexto familiar, saúde e outros. Dessas, observa-se que o contexto familiar e 
as questões referentes a problemas de saúde dos alunos são mais recorrentes:

Diretora: “Gente, esse menino tem problema. Não tem? Ele é... hiperativo?

(Anotações de campo, Conselho 3, 6B, 17/02/2016)

Professora de Matemática: "Não tem mãe, não tem pai. Tem que chamar a vó. Ele mora com a vó."

(Anotações de campo, Conselho 3, 6B, 17/02/2016)

Professor não identificado: "Morou um tempo em abrigo." (Anotações de campo, Conselho 1, 6A, 25/07/2015)

Somente na categoria nomeada de Produção Acadêmica é que as frases com adjetivos que têm relação direta com a escolarização foram elencadas. Elas foram expressos, em sua grande maioria, de forma negativa: muito fraco, fraquinha, baixo rendimento, caso grave, tem bastante dificuldade, não entregou trabalho, repetente, ele não faz, relaxado, bomba, coisa, reprovado, etc. Mesmo que de forma discreta, adjetivos positivos são também observados, como: boa, bom, destaque, excelente, maravilhoso, ótimo, esperto e inteligente. Exemplificam-se nas falas abaixo:

Professora de História: "Bom aluno. Ele não é destaque?"

Professora não identificada: "Ele é tão esperto que às vezes ele extrapola."

(Anotações de campo. Conselho 2, 6B, 10/11/2015)

Professora de Educação Física: "Ela é fraquinha, mas é aquela aluna mediana."

(Anotações de campo. Conselho 2, 6B, 11/10/2016)

Professora de Geografia: "Gente, ele já é repetente!"

(Anotações de campo. Conselho 2, 6B, 11/10/2016)

Professora de Matemática: "Mas ele não fez nada de propósito. Por... por ele achar que é repetente, que ele ia passar. Ele não fez nem as recuperações..."

(Anotações de campo. Conselho 2, 6B, 11/10/2016) 
Professora de Matemática: "Não. É uma turma tão, tão boa, sabe. Pra gente pegar e jogar essa bomba."

(Anotações de campo. Conselho 3, 6D, 17/02/2016)

Os dados empíricos demonstraram, como em Fernandes e Freitas (2007), que os professores avaliam aspectos além dos conhecimentos propagados pela escola, como valores e atitudes. Verifica-se que a maioria das frases julgadoras constatadas possui características voltadas ao Comportamento, Hexis Corporal e ao Contexto Social e não às questões acadêmicas. As frases relacionadas às questões acadêmicas expressam-se, em sua maioria, com justificativas pouco formuladas, como: fraco, tem muita dificuldade, caso grave, repetente, fraquinha; não faz tarefas, etc. O pouco aprofundamento nas justificativas pelo baixo desempenho dos alunos demonstra a falta de conhecimento sobre ele, bem como sobre a prática e objetivos docentes. As falas de professores que demonstram relativa especificidade sobre as dificuldades dos alunos são raras.

Além das adjetivações, destaca-se, como já foi evidenciado de forma semelhante por Bourdieu e Saint-Martin (2015), o que confirmaram Catani e Gallego (2009, p. 22), quando ressaltam que:

[...] os alunos são avaliados quanto à disciplina, comprometimento, apoio familiar, dedicação aos estudos e à escola, vontade de aprender, cumprimento das obrigações, lugar que ocupa no interior da sala, entre outros componentes.

Há, como esperado pelas disposições já inculcadas nos professores, resistência a mudanças, o que é agravado pela quase ausência de disciplinas que tenham a temática da avaliação nos cursos de licenciatura, para que, assim, uma possibilidade de reestruturação seja plausível.

Observou-se que os conselhos ao longo do ano letivo denotam características diferenciadas, sendo que o último tem maior peso deliberativo, no sentido de que formalmente se decide pela aprovação ou reprovação do aluno.

Após apreciação geral sobre a turma, conversa-se individualmente a respeito de cada caso. Nos dois primeiros 
conselhos de classe observados, a fala da equipe pedagógica se pautou em: "Vamos falar dos casos mais críticos" (Anotações de campo. Conselho 1, 6A, 25/07/2015).

Nos dois primeiros conselhos, cada aluno era citado, mas os que não apresentavam problemas de notas ou de comportamento eram somente mencionados e logo substituídos por outros na discussão. São os casos "ok".

As resoluções previstas para os problemas são terceirizadas, no sentido de se chamar os pais pra resolver, encaminhar para profissionais de saúde, etc. Como constatado por Mattos (2005, p. 226), os professores tentam se eximir "de possíveis culpas quanto as suas responsabilidades para com o processo de aprendizagem e de socialização de seus alunos e alunas, recorrendo a recursos diversos".

Com base nas observações realizadas, juntamente com o caderno de campo e os boletins escolares, pôde-se constatar que alguns alunos tiveram seu destino escolar traçado já no segundo conselho de classe e que, de certa forma, todas as "previsões" aconteceram.

Importante salientar que a ajuda ou a não ajuda destinada aos alunos esteve em dar oportunidade para que estes realizassem atividades extras para a complementação da nota e não necessariamente na preocupação com a aprendizagem do conteúdo com o qual o estudante encontrava dificuldade. Algumas falas dos professores e da equipe pedagógica demonstraram a maneira de realizar a tal ajuda:

Professor não identificado: "Só em uma não reprova."

Professor não identificado responde: "Dá trabalhinho."

(Anotações de campo. Conselho 2, 6C, 10/11/2015)

Pedagoga: "Deem trabalho pra dificultar um pouquinho..."

Pedagoga: "Estamos dando oportunidade, não vamos passar de graça. Vamos dar trabalho."

(Anotações de campo. Conselho 2, 6C, 10/11/2015)

O fato de os professores ajudarem os alunos com atividades extras para que estes melhorem suas notas e possam ser aprovados demonstra que a preocupação apresentada pelos docentes está atrelada somente ao aspecto quantitativo, 
não havendo maiores preocupações com a aprendizagem de fato. O conteúdo a ser aprendido não é valorizado, ao passo que o esforço do aluno em fazer tarefas extras é tido como positivo, ação que possibilitaria uma aprovação. Essa forma de interpretar quantitativamente o conhecimento acaba por ser uma moeda de troca, uma estratégia de dominação no ambiente escolar:

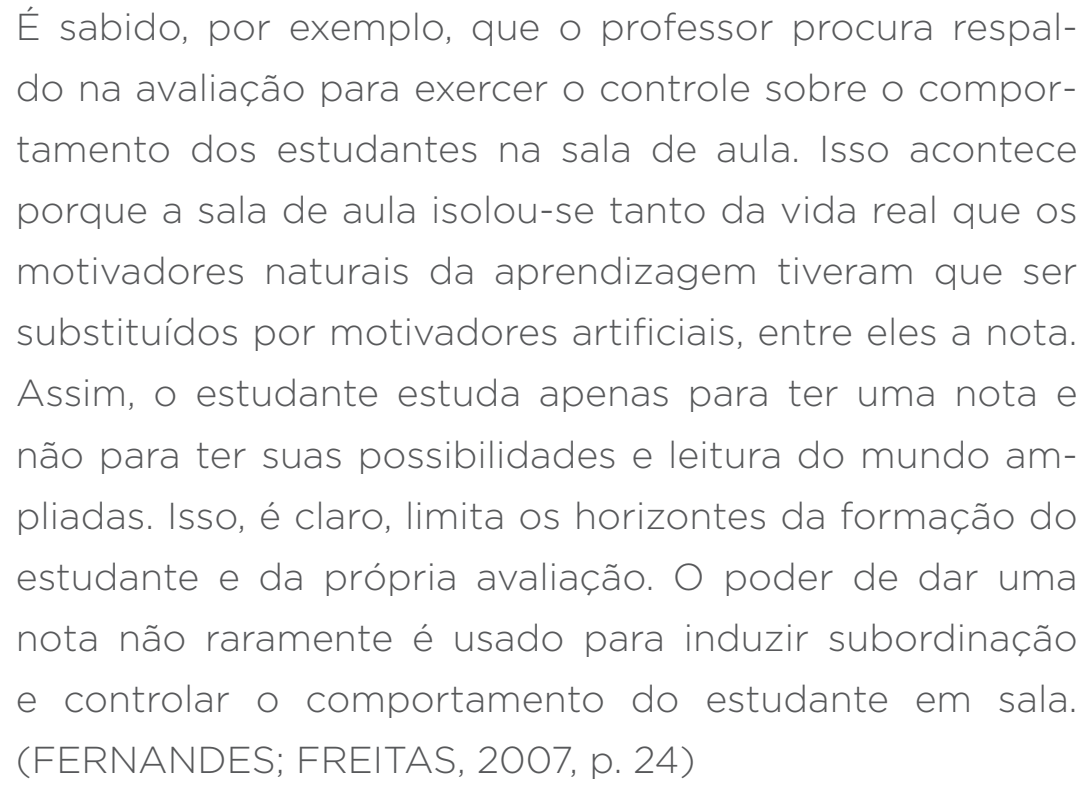

A ação pedagógica, segundo Bourdieu (2010), é um dos exemplos fundamentais da violência simbólica, como um processo de imposição dissimulada de um arbitrário cultural e também de imposição de formas de ser, saber e agir na instituição escolar. O aluno sempre será subordinado, sempre reconhecerá a autoridade pedagógica de forma não intencional, pois o docente é o possuidor dos saberes. Por outro viés, Rojas (2007) menciona que os alunos estabelecem uma relação mercantil com as notas, o que dificulta o envolvimento com seu próprio aprendizado. Tal relação, a pressão dos pais para a manutenção dos métodos tradicionais de avaliação e a burocracia escolar estabelecem dificuldades para a inovação das práticas avaliativas. Entende-se que há apego às notas e à classificação e que, nesse sentido, a tendência é que as práticas escolares avaliativas se reproduzam, apresentando-se no habitus estudantil e professoral, na formação dos agentes.

O habitus professoral, constituído na prática docente, traduz-se na incorporação de práticas pedagógicas e posturas 
corporais da ação docente, capazes de orientar as ações de maneira inconsciente e sistemática. Tais disposições e ações do professor são responsáveis por disposições e ações que se imprimem nos alunos, como reações ao vivenciado sistematicamente, como repostas imediatas e objetivas. Os comportamentos dos professores geram comportamentos nos alunos (SILVA, 2011).

Verifica-se, assim, que as expectativas dos professores sobre os alunos desencadeiam ações que favorecem o acontecimento de profecias. Explicitamente os alunos ajudados tiveram seu destino escolar favorecido; já quanto àqueles não ajudados, observou-se o contrário. Rosenthal e Jacobson (1991/1968) descrevem achados em uma pesquisa realizada em uma instituição de ensino primário nos Estados Unidos, em que professores foram levados a crer que determinado grupo de alunos, escolhidos de forma aleatória, tinha maior potencial de desenvolvimento que outros. Os autores evidenciaram no estudo que a expectativa dos professores é um determinante não intencional da capacidade dos alunos, ou seja, aquilo que o docente espera como resultado do aluno acaba por acontecer, fenômeno a respeito do qual os autores criaram o conceito de "profecia autorrealizadora". Se o professor espera bom desempenho do aluno, de fato o rendimento deste acontecerá conforme o esperado, ao passo que, se a expectativa for oposta, o resultado também o será: "O professor consegue menos, porque espera menos" (ROSENTHAL; JACOBSON, 1991/1968, p. 258).

Rosenthal e Jacobson (1991/1968) verificaram que as expectativas dos professores determinam o aumento do desempenho intelectual do aluno e que isso parece ocorrer devido ao maior acompanhamento dos professores aos alunos tidos como mais promissores. O professor investe naquele que pensa que dará resultado positivo e não naquele aluno que mais precisa, naquele visto como sem potencial.

Os alunos com maiores dificuldades são precocemente condenados à reprovação e de fato reprovam, pois não são estabelecidas estratégias para que o contrário possa acontecer. Os professores, equipe pedagógica e diretiva não acreditam que o aluno possa mudar, não investem nele e, dessa maneira, parecem trabalhar para que a profecia seja cumprida. 
Também se justifica a reprovação como forma de punir os pais que não seguem as orientações dadas pela escola para encaminhamentos externos, punição essa que é direcionada ao aluno.

Sá Earp (2006, p. 314), que realizou um estudo sobre a cultura da repetência em escolas cariocas, levantou a tese de que "os alunos são reprovados pelos professores porque há uma lógica que os faz reprovar". Assim, a autora constatou que a repetência acontece não porque os alunos não aprendem, ou porque os professores não sabem ensinar, mas sim pela lógica cultural da sociedade que está nas representações docentes. $\mathrm{O}$ professor ensina para alguns alunos e não para todos. De acordo com a autora, a sala de aula é organizada de acordo com uma estrutura, a qual denominou centro-periferia. Alunos-centro são os escolhidos pelos professores para serem ensinados, ao passo que os alunos-periferia são aqueles que são negligenciados. Verificou que, de uma maneira geral, todos os professores:

[...] acreditam que a reprovação serve para selecionar, "filtrar", os "bons" dos "maus" alunos; que os alunos são reprovados porque "não sabem nada", "não se interessam", "não querem nada" e "não têm jeito". Os professores não acham estranho reprovar 50\% de uma turma, outros acreditam que a reprovação deveria ser maior ou que é normal reprovar uma turma inteira. (SÁ EARP, 2006, p. 314-315)

Sá Earp (2010, p. 26) menciona que no sistema de ensino brasileiro, culturalmente,

[...] parece existir uma crença generalizada de que alguns alunos são menos capazes de aprender. Segundo essa crença, não adianta ensinar, porque alguns estudantes não vão mesmo aprender.

Assim, acabam por ser reprovados ou agraciados com "ajudas" sem critérios definidos. A cultura da repetência constitui-se em prática pedagógica, delineando-se em habitus professoral; é o saber fazer docente que se apresenta de forma regular, compartilhado no campo, gerando consequências diretas na vida dos estudantes. 
A partir da análise dos dados empíricos, compreende-se que os agentes escolares participantes dos conselhos de classe observados focalizam a avaliação do aluno em aspectos externos à aprendizagem de fato. A tendência é considerar o caráter, a postura, o comprometimento, a composição familiar e se esse estudante possui ou não problemas de saúde. Aspectos da aprendizagem são superficialmente julgados, e os professores reduzem o trimestre de aulas a um adjetivo isolado: aluno "fraco". Mais uma vez a escola é negligente, pois solicita outros meios para resolução das dificuldades dos seus alunos, que não estão na escola, terceirizando assim as possíveis soluções.

Os adjetivos sociais tornam-se escolares. A escola continua a ser, como evidenciado por Bourdieu e Saint-Marin (2015), uma máquina que transforma adjetivos sociais em escolares, classificando os estudantes de forma dissimulada, subjetiva, sem critérios evidentes ou padronizados. Não obstante, também se exerce no espaço escolar a lógica da fabricação de hierarquias de excelência descrita por Perrenoud (1996), pois os docentes, juntamente com a equipe pedagógica e diretiva, decidem pelo êxito ou fracasso dos estudantes, classificando-os como "fracos" ou "destaques" e, assim, hierarquizando-os. Para Perrenoud (1996), os saberes e o saber fazer dos alunos estão traduzidos em hierarquias explícitas, normas, as quais trazem importância simbólica e consequências para o percurso escolar. Essa norma de excelência funciona como o ponto de referência que induz a uma ordem, uma classificação; assim, as práticas específicas acabam por gerar competição entre os praticantes da mesma ação, os quais buscam aproximar-se da perfeição. Os participantes dessa dinâmica, no caso os estudantes, ocupam um lugar nessa hierarquia, sendo que os que se aproximam da excelência são julgados como os mais inteligentes, os alunos "destaque", ao passo que os que mais se distanciam são os adjetivados como "incapazes", "fracos". Nesse meio, a escola tem poder de lei sobre a construção da representação do indivíduo sobre si e sobre o outro, e, atribuindo a cada aluno o seu nível de excelência, fabrica a imagem da realidade imposta como a realidade correta, categorizando e hierarquizando. 


\section{CONSIDERAÇÕES FINAIS}

A realidade da instituição pesquisada mostra toda a complexidade das relações que nela acontecem, como de fato se espera pelas diversas interações que o campo escolar permite.

As observações e contínua organização dos dados empíricos possibilitaram identificar, assim como em Dalben (1995), que os docentes têm visão compartimentada do aluno, em que a nota é o critério de qualidade. Se a média seis é atingida, o aluno que é "ok" está dentro da normalidade, sugestionando-se que ele aprendeu o necessário, o mínimo para a promoção ao sétimo ano. No entanto, além de questões quantitativas, outros critérios são considerados relevantes ao julgar o aluno, especificadamente se ele corresponde ou não aos padrões sociais e de conduta esperados, expressos em seu comportamento e na composição do seu núcleo familiar (categorias Comportamento e Contexto Social).

Os dados empíricos aqui mostrados possibilitam corroborar a visão de Bourdieu e Saint-Martin (2015) por evidenciar que, além das questões acadêmicas, estão presentes, nas discussões entre os educadores nos momentos conjuntos de avaliação, outros fatores, externos ao escolar, como a atitude dos pais, o esforço, o comportamento (se brinca em sala, se é preguiçoso, se é mentiroso, dissimulado, organizado, responsável, entre outros), bem como a sua hexis corporal (bonitinho, gordinho, loirinho, etc.). As categorias Hexis Corporal, Contexto Social e Comportamento foram mais representativas em comparação às frases que se enquadram na categoria Produção Acadêmica. Essa afirmação faz refletir sobre a qualidade e a função da educação que se intenciona. Ora, se a escola enquanto instituição de ensino não se responsabiliza pela aprendizagem, ou seja, não se atém a critérios de produção acadêmica ao avaliar e deferir, qual a sua finalidade? O que intenciona ao considerar critérios extraescolares ao avaliar a aprendizagem? Não se pretende aqui responder de forma absoluta tais questionamentos. Entretanto, defende-se que a escola contribui para a construção de estigmas, classificando e adjetivando de forma dissimulada e inconsciente os estudantes, sendo executora de violência simbólica, em sua relação de dominação e imposição de um arbitrário cultural. 
A escola investigada funciona como uma máquina de conversão de julgamentos sociais em escolares (BOURDIEU; SAINT-MARTIN, 2015) e, dessa forma, o juízo professoral emitido aos alunos no período escolar passa a acompanhá-los para a vida, repercutindo no seu destino acadêmico. A escola é um dos meios socializadores mais representativos na vida do estudante, na qual ele está se constituindo e sendo constituído, forjando seu habitus.

Os eventos dos conselhos de classe observados mostram ser, como naqueles descritos por Mattos (2005), Sá Earp (2006, 2012, 2014), Sá Earp e Prado (2016) e Dalben (1995, 2004), um espaço de exclusão, em que o professor não questiona as suas práticas, sua metodologia e acaba por projetar a culpa pelo fracasso escolar dos alunos neles mesmos, em sua condição familiar e de saúde. Não houve, em nenhum momento durante as observações dos conselhos de classe, indagações/reflexões dos professores sobre as suas práticas. O problema e a solução para a aprendizagem estiveram sempre atrelados a fatores externos.

O sistema escolar tende a manter a homogeneidade, excluindo de forma dissimulada aqueles que nela não se encaixam, sem que esses alunos ou professores percebam, pois tudo se dá pelos imperativos do campo. Na escola pesquisada, a exclusão acontece pela negligência, no sentido de que ela se isenta das responsabilidades educativas que the caberiam. Nossos resultados de pesquisa corroboram os de Dalben (1995), ao evidenciar que, alicerçados na ideologia do dom e do mérito, os professores muitas vezes, ao avaliar, não se dão conta de que consideram aspectos da aprendizagem que acontecem tanto dentro como fora da escola, contribuindo para o pensamento de que as discrepâncias sociais são naturais.

Pode-se constatar que a avaliação classificatória está enraizada na cultura da escola pesquisada, sendo alimentada pelo habitus professoral que tende a se reproduzir dentro da instituição, pois faz parte do saber fazer que é compartilhado entre os docentes, atuando no campo.

Mesmo que a legislação e as orientações oficiais para a realização da avaliação da aprendizagem e o andamento dos 
conselhos de classe mostrem-se favoráveis à aprendizagem qualitativa, sendo momento para o professor rever e reorganizar seu planejamento, os exercícios desses eventos continuam a favorecer a exclusão e a manutenção de uma prática classificatória e burocrática. É a conservação de um sistema que se instalou no final do século XIX, com a institucionalização do sistema classificatório de avaliação (SOUZA, 1998).

\section{REFERÊNCIAS}

ALVES-MAZZOTTI, Alda Judith. O método nas ciências sociais. In: ALVES-MAZZOTTI, Alda Judith; GEWANDSZNAJDER, Fernando. O método nas ciências naturais e sociais: pesquisa quantitativa e qualitativa. São Paulo: Pioneira, 1998. p. 108-203.

BARDIN, Laurence. Análise de conteúdo. Tradução de Luís Antero Reto e Augusto Pinheiro. São Paulo: Edições 70, 2011.

BOURDIEU, Pierre. 0 senso prático. Tradução de Maria Ferreira. Petrópolis, RJ: Vozes, 2009.

BOURDIEU, Pierre. A violência simbólica. In: BOURDIEU, Pierre. A dominação masculina. Tradução de Maria Helena Kühner. Rio de Janeiro: Bertand Brasil, 2010.

BOURDIEU, Pierre. Os três estados do capital cultural. In: NOGUEIRA, Maria Alice; CATANI, Afrânio (Org.). Escritos de educação. Tradução de Vera S. V. Falsetti e José Carlos Garcia Durand. 16. ed. Petrópolis, RJ: Vozes, 2015. p. 43-72.

BOURDIEU, Pierre; SAINT-MARTIN, Monique de. As categorias do juízo professoral. In: NOGUEIRA, Maria Alice; CATANI, Afrânio (Org.). Escritos de educação. Tradução de Vera S. V. Falsetti e José Carlos Garcia Durand. 16. ed. Petrópolis, RJ: Vozes, 2015. p. 205-241.

BRASIL. Lei n. 5.692/71. Fixa Diretrizes e Bases para o ensino de $1^{\circ}$ e $2^{\circ}$ graus, e dá outras providências, 11 de agosto de 1971. Diário Oficial [da] República Federativa do Brasil, Brasília, DF, 1971a. Disponível em: <http:/| www2.camara.leg.br/legin/fed/lei/1970-1979/lei-5692-11-agosto-1971-357752publicacaooriginal-1-pl.html>. Acesso em: 10 fev. 2017.

CATANI, Denice Barbara; GALLEGO, Rita de Cássia. Avaliação. São Paulo: Editora Unesp, 2009.

COMPIANI, Ruth. Colégio Estadual do Paraná: classes integrais (experimentais) 1960/67. 1965.

DALBEN, Ângela Imaculada Loureiro de Freitas. Trabalho escolar e conselho de classe. 3. ed. Campinas, SP: Papirus, 1995.

DALBEN, Ângela Imaculada Loureiro de Freitas. Conselhos de classe e avaliação: perspectivas na gestão pedagógica da escola. Campinas, SP: Papirus, 2004. 
FERNANDES, Cláudia de Oliveira; FREITAS, Luiz Carlos de. Indagações sobre currículo: currículo e avaliação. Brasília, DF: Ministério da Educação, Secretaria de Educação Básica, 2007.

FORQUIN, Jean-Claude. Escola e cultura: as bases sociais e epistemológicas do conhecimento escolar. Tradução de Guacira Lopes Louro. Porto Alegre: Artes Médicas, 1993.

LEITE, Lilian Ianke. Conselho de classe: a historicidade de uma prática entre os fazeres ordinários da escola (1950-1990). 2012. 239 f. Tese (Doutorado em Educação) - Universidade Federal do Paraná, Curitiba, 2012.

LESSARD-HÉBERT, Michelle; GOYETTE, Gabriel; BOUTIN, Gérald. Investigação qualitativa: fundamentos e práticas. Tradução de Maria João Reis. Lisboa: Instituto Piaget, 2005.

MACHADO, Lucília Regina de Souza. Prefácio. In: DALBEN, Ângela Imaculada Loureiro de Freitas. Trabalho escolar e conselho de classe. 3. ed. Campinas, SP: Papirus, 1995.

MAFRA, Leila de Alvarenga. A sociologia dos estabelecimentos escolares: passado e presente de um campo de pesquisa em re-construção. In: ZAGO, Nadir; CARVALHO, Marília Pinto de; VILELA, Rita Amélia Teixeira (Org.). Itinerários de pesquisa: perspectivas qualitativas em sociologia da educação. Rio de Janeiro: DP\&A, 2003.

MATTOS, Carmen Lúcia Guimarães de. O conselho de classe e a construção do fracasso escolar. Educação e Pesquisa, São Paulo, v. 31, n. 2, p. 215-228, maio/ago. 2005. Disponível em: <http://educa.fcc.org.br/pdf/ep/v31n02/ v31n02a05.pdf>. Acesso em: 20 jun. 2015.

NOGUEIRA, Claudio Marques Martins; NOGUEIRA, Maria Alice. Bourdieu \& a educação. Belo Horizonte: Autêntica, 2014.

OLIVEIRA, Jaqueline Maas. Categorias do juizo professoral em conselhos de classe: entre interpretações, julgamentos e implicações. 2017. 222f. Dissertação (Mestrado em Educação) - Universidade Federal do Paraná, Curitiba, 2017.

ORENGA, Dayane Cristina; CORREAA, Isabele Miranda. Transição do aluno do $5^{\circ}$ ano para $06^{\circ}$ ano do ensino fundamental: expectativas e angústias das crianças e professores. 2014. 98 f. Trabalho de Conclusão de Curso (Licenciatura em Pedagogia) - Setor de Educação, Universidade Federal do Paraná, Curitiba, 2014.

PAPI, Silmara de Oliveira Gomes. Conselho de classe: que colegiado é esse? Estudos em Avaliação Educacional, São Paulo, v. 26, n. 62, p. 480-518, maio/ago. 2015.

PERRENOUD, Philippe. La construcción del èxito y del fracaso escolar. Madrid: Ediciones Morata, 1996.

RESENDE, Tânia de Freitas. Sistema de ensino. In: CATANI, Afrânio Mendes. Vocabulário Bourdieu. Belo Horizonte: Autêntica, 2017.

ROCHA, Any Dutra Coelho da. Conselho de classe: burocratização ou participação? Rio de Janeiro: Francisco Alves, 1982. 
ROJAS, Hugo de los Santos. Formação do professor do ensino básico e a avaliação educacional. Estudos em Avaliação Educacional, São Paulo, v. 18, n. 37, p. 7-40, maio/ago. 2007.

ROSENTHAL, Robert; JACOBSON, Lenore. Profecias auto-realizadoras na sala de aula: as expectativas dos professores como determinantes não intencionais da capacidade intelectual dos alunos. In: PATTO, Maria Helena Souza (Org.). Introdução à psicologia escolar. Tradução de Maria Lídia Sica Szumanski. São Paulo: T. A. Queiroz, 1991. p. 258-295. Trabalho original publicado em 1968.

SÁ EARP, Maria de Lourdes. A cultura da repetência em escolas cariocas. 2006. 310 f. Tese (Doutorado em Sociologia e Antropologia) - Instituto de Filosofia e Ciências Sociais, Universidade Federal do Rio de Janeiro, Rio de Janeiro, 2006.

SÁ EARP, Maria de Lourdes. Antropologia e educação: um estudo sobre a repetência. ENFOQUES: Revista Eletrônica dos Alunos do PPGSA/IFCS/UFRJ, Rio de Janeiro, v. 9, n. 1, p. 10-29, ago. 2010. Disponível em: <http://www. enfoques.ifcs.ufrj.br/ojs/index.php/enfoques/article/view/97>. Acesso em: 10 jan. 2017.

SÁ EARP, Maria de Lourdes. O juízo professoral: um estudo em uma escola pública da cidade do Rio de Janeiro. In: ENCONTRO NACIONAL DE DIDÁTICA E PRÁTICA DE ESTUDOS, 16., 2012, Campinas. Anais.... Araraquara: Junqueira \& Morin, 2012, livro 3, p. 1970-1981. Disponível em: <http://www.infoteca. inf.br/endipe/smarty/templates/arquivos_template/upload_arquivos/acervo/ docs/2019b.pdf>. Acesso em: 12 ago. 2015.

SÁ EARP, Maria de Lourdes. Etnografia no conselho de classe: avaliação e juízo professoral. In: CONGRESSO IBERO-AMERICANO DE POLÍTICA E ADMINISTRAÇÃ̃O DA EDUCAÇÃO, 4.; CONGRESSO LUSO-BRASILEIRO DE POLÍTICA E ADMISTRAÇÃO DA EDUCAÇÃO, 7., 2014, Porto. Anais... Goiânia: Anpae. Disponível em: <http://www.anpae.org.br/IBERO_AMERICANO_IV/GT1/ GT1_Comunicacao/Maria deLourdesSaEarp_GT1_integral.pdf>. Acesso em: 2 fev. 2016.

SÁ EARP, Maria de Lourdes; PRADO, Ana Pires. O juízo professoral em Conselhos de Classe de escolas da cidade do Rio de Janeiro. Revista de Educação Pública, Cuiabá, v. 25, n. 58, p. 33-53, jan./abr. 2016. Disponível em: $<$ http://periodicoscientificos.ufmt.br/ojs/index.php/educacaopublica/article/ view/1699>. Acesso em: 14 ago. 2016.

SILVA, Marilda da. Habitus professoral e habitus estudantil: uma proposição acerca da formação de professores. Educação em Revista, Belo Horizonte, v. 27, p. 335-369, dez. 2011.

SOUZA, Rosa de Fátima. Templos de civilização: a implementação da escola primária graduada no Estado de São Paulo (1890-1910). São Paulo: Fundação Editora da Unesp, 1998.

Recebido em: 13 JUNHO 2017

Aprovado para publicação em: 10 SETEMBRO 2018 